\title{
Premenstrual Syndrome Diagnosis: A Comparative Study between the Daily Record of Severity of Problems (DRSP) and the Premenstrual Symptoms Screening Tool (PSST)
}

\section{Diagnóstico de síndrome pré-menstrual: um estudo comparativo entre o relato diário da gravidade dos problemas (DRSP) e o instrumento de rastreamento de sintomas pré-menstruais (PSST)}

\author{
Aline Henz ${ }^{1}$ Charles Francisco Ferreira ${ }^{1}$ Carolina Leão Oderich ${ }^{1}$ Carin Weirich Gallon ${ }^{1}$ \\ Juliana Rintondale Sodré de Castro ${ }^{1}$ Maiara Conzatti ${ }^{1}$ Marcelo Pio de Almeida Fleck ${ }^{1}$ \\ Maria Celeste Osório Wender ${ }^{1}$
1 Universidade Federal do Rio Grande do Sul, Porto Alegre, RS, Brazil Rev Bras Ginecol Obstet 2018;40:20-25.
Address for correspondence Aline Henz, MSc, Rua Ramiro Barcelos, 2350, 90035-903, Porto Alegre, RS, Brazil (e-mail: line.henz@gmail.com).

\begin{abstract}
Objective To validate the premenstrual symptoms screening tool (PSST) in relation to the daily record of severity of problems (DRSP) for premenstrual syndrome (PMS) and premenstrual dysphoric disorder (PMDD) diagnoses.

Methods A cross-sectional study with 127 women (20-45 years) with PMS complaints. The women were evaluated in terms of weight, height and body mass index (BMI). After using the primary care evaluation of mental disorders (PRIME-MD) questionnaire to exclude the diagnosis of depression, the PSST was completed and the women were instructed to fill out the DRSP for two consecutive menstrual cycles. The agreement between the two questionnaires was assessed by the Kappa $(\mathrm{k})$ and the prevalence-adjusted, bias-adjusted kappa (PABAK) values.

\author{
Keywords \\ - diagnosis \\ - questionnaire \\ - signs and symptoms \\ - premenstrual \\ syndrome \\ - premenstrual \\ dysphoric disorder
}

Results Two-hundred and eighty-two women met the eligibility criteria and answered the PSST. The DRSP was completed for two cycles by 127 women. The percentages of women with PMS and PMDD diagnoses by the DRSP were $74.8 \%$ and $3.9 \%$ respectively; by PSST, the percentages were $41.7 \%$ and $34.6 \%$ respectively. The number of patients considered "normal" (with symptoms below the threshold for the diagnosis of PMS) was similar in both questionnaires. There was no agreement (Kappa $=0.12$ ) in the results of PMS/ PMDD diagnosis (the PABAK coefficient confirmed this result $=0.39$ ). The PSST had a high sensitivity (79\%) and a low specificity (33.3\%) for PMS/PMDD diagnosis.
\end{abstract}

received

September 22, 2017

accepted

October 5, 2017

published online

November 13, 2017
Copyright $\odot 2018$ by Thieme Revinter

Publicações Ltda, Rio de Janeiro, Brazil
License terms

(c) $(1) \$$ 10.1055/s-0037-1608672. ISSN 0100-7203. 


\section{Resumo}

Conclusion The PSST should be considered a diagnostic screening tool. Positive PMS/PMDD cases by PSST should be further evaluated by DRSP to confirm the diagnosis.
Objetivo Validar o instrumento de rastreamento de sintomas pré-menstruais (PSST) em relação ao relato diário da gravidade dos problemas (DRSP) para o diagnóstico de síndrome pré-menstrual (SPM) e de transtorno disfórico pré-menstrual (TDPM).

Métodos Um estudo transversal com 127 mulheres entre 20 e 45 anos com queixas de SPM. As mulheres foram avaliadas quanto ao peso, à altura e ao índice de massa corporal (IMC). Depois de excluir o diagnóstico de depressão pelo questionário de avaliação de distúrbios mentais para atenção primária (PRIME-MD), o PSST foi respondido e as mulheres receberam orientações sobre como preencher o DRSP por dois meses. A concordância entre os dois questionários foi conduzida através do índice de Kapa (k) e pelo PABAK.

Resultados Duzentos e oitenta e duas mulheres com critérios elegíveis responderam ao PSST. O DRSP foi preenchido por dois ciclos por 127 mulheres. As porcentagens de mulheres com diagnósticos de SPM e de TDPM pelo DRSP foram de $74,8 \%$ e 3,9\%, respectivamente; pelo PSST, as porcentagens foram de $41,7 \%$ e $34,6 \%$, respectivamente. O número de pacientes consideradas "normais" (com sintomas abaixo do necessário para o diagnóstico de SPM) foi similar nos dois questionários. Análises demonstraram não haver concordância entre ambos os instrumentos para os resultados diagnósticos de SPM e TDPM (Kappa $=0,12$, coeficiente de PABAK $=0,39$ ). Para o diagnóstico de SPM/TDPM, o PSST apresentou uma alta sensibilidade (79\%) e baixa especificidade $(33,3 \%)$.

Conclusão O PSST é considerado uma ferramenta de triagem. Conclui-se que casos positivos de SPM/TDPM pelo PSST devem ser melhor investigados pelo DRSP para confirmar o diagnóstico.

\section{Introduction}

Premenstrual syndrome (PMS) is defined as a recurring pattern of symptoms that occur during the premenstrual phase and decline soon after the start of menses. ${ }^{1}$ It is characterized by physical, affective, and behavioral symptoms that significantly impair the daily lives of women, including work and personal activities, during the luteal phase and spontaneously resolve within a few days of the onset of menstruation. ${ }^{2}$

About $50-80 \%$ of women report that they experience at least some PMS symptoms during the premenstrual phase, and the condition occurs in approximately $30-40 \%$ of reproductive females that report symptoms of PMS, who end up requiring some type of treatment or better attention. ${ }^{1-8}$

Women with severe symptoms, including at least one disabling affective symptom, to the extent of causing marked functional impairment are classified as having premenstrual dysphoric disorder (PMDD). It is estimated that PMDD affects from $3-8 \%$ of menstruating women. ${ }^{9}$

The symptoms of PMS can be very similar to those of other diseases, such as depression and anxiety crisis, among others; therefore, an accurate prospective evaluation of the symptoms is required to make the diagnosis. The International Society for Premenstrual Disorders (ISPMD) recommends that the diagnosis is only confirmed after reviewing the data recorded for 2 consecutive menstrual cycles. ${ }^{10}$
The use of structured questionnaires is established, and several validated diagnostic techniques are available. The most accepted and widely used system is the daily record of severity problems (DRSP), a prospective, self-administered questionnaire. To use the DRSP as a diagnostic tool for PMS, it is necessary that the patient fills it for at least two consecutive menstrual cycles. However, this requirement limits this practical applicability in the day-to-day care of patients with premenstrual symptoms. ${ }^{11-13}$

The premenstrual symptoms screening tool (PSST) is a retrospective questionnaire completed during clinical consultation with the patient. It is a screening tool used to identify women who suffer from severe PMS/PMDD. ${ }^{14}$ It is less timeconsuming and more practical than two cycles of prospective charting. However, the retrospective assessment of symptoms has limited value and requires validation against an established prospective technique, such as the DRSP. ${ }^{11}$

Based on these considerations, the aim of this study was to validate the PSST in relation to the DRSP for the diagnosis of PMS and PMDD.

\section{Methods}

The selected women read and signed the informed consent, which was approved by the Committee of Ethics in Research of the institution (number 15-0087). 
This was a cross-sectional study with participants recruited by local media (TV, radio or newspaper) announcements. The study was developed in a hospital in the state of Rio Grande do Sul, Brazil, during the period from August of 2014 to December of 2015.

The participants were women between 20 and 45 years old with PMS complaints and cyclical menses. The exclusion criteria were: menopause, use of any continuous hormonal contraception, use of antidepressants or depression diagnosis.

It was determined that in order to get a Kappa coefficient of at least 0.7 , with $80 \%$ power, and a level of significance of $5 \%$, the sample size should comprise at least 123 valid questionnaires. The women included were evaluated in terms of weight, height and body mass index (BMI), and they all answered the primary care evaluation of mental disorders (PRIME-MD) questionnaire (Module mood). In the cases of positive screening for depression, the diagnostic and statistical manual of mental disorders (DSM-V) questionnaire was applied to establish the diagnosis. The depressive women were excluded from the study and referred for psychiatric care. After the PSST (-Supplemental Material 1) was completed by the women, the DRSP (-Supplemental Material 2) was handed out to be filled out daily for two consecutive menstrual cycles. ${ }^{12-18}$

Statistical analysis was performed using the software SPSS, version 18.0 (SPSS Inc., Chicago, IL, USA). Continuous variables were expressed as mean \pm standard deviation (SD) and categorical variables were expressed as absolute $(n)$ and relative ( $n \%)$ frequencies. The agreement between the two questionnaires was evaluated by calculating the Kappa $(\mathrm{k})$ and the prevalence-adjusted, bias-adjusted kappa (PABAK) values. Kappa is an agreement measure beyond that agreement expected to occur by chance. The Kappa expected, according to Altman, ${ }^{19}$ was 0.8 - with a range of $0.643-0.893$, with a $95 \%$ confidence interval $(95 \% \mathrm{CI})$. Additionally, an interval-by-interval basis was calculated by the PABAK. ${ }^{20}$ The PABAK is a simple and flexible index, representing a method for calculating interrater reliability between two raters (for example, DRSP and PSST) using an ordinal rating scale of categories (such as, Normal, PMS and PMDD), suitable for nominal scales only. The PABAK value was calculated using the computer program for Epidemiologists WinPEPI, version 11.65 (for $2 \times 2$ categories tables), or the PABAK-OS calculator, available at singlecaseresearch.org (for table formats other than $2 \times 2$ categories). For all analyses, significance was set at $5 \%$.

\section{Results}

Overall, 377 women signed up to participate in the study; however, only 282 (74\%) of them were considered eligible due to category recruitment and thus, these women answered the PSST. The baseline characteristics of these women are shown in -Table 1.

Of the eligible women, 135 (55\%) did not fully complete all the two cycles of the daily questionnaire (DRSP). Only 127 (45\%) women completed the study- including the 2 cycles of the DRSP. These women were considered to have fully participated in this study and represent the full analysis set (-Fig. 1).
Table 1 Sociodemographic characteristics of the women who completed the PSST and filled out the DRSP for 2 consecutive menstrual cycles

\begin{tabular}{|c|c|}
\hline Variables & $(n=127)$ \\
\hline Age (years) - Mean \pm SD [Min-Max] & $\begin{array}{l}33.7 \pm 6.6 \\
{[20.0-45.0]}\end{array}$ \\
\hline \multicolumn{2}{|l|}{ Skin color $-n(n \%)$} \\
\hline White & $112(88.2)$ \\
\hline Not white & $15(11.8)$ \\
\hline \multicolumn{2}{|l|}{ Educational level - $n(n \%)$} \\
\hline Elementary & $3(2.4)$ \\
\hline High school & $37(29.1)$ \\
\hline Academic & $85(66.9)$ \\
\hline \multicolumn{2}{|c|}{$\begin{array}{l}\text { Using non-continuous regimens of combined hormonal } \\
\text { contraceptive }-n(n \%)\end{array}$} \\
\hline Yes & $72(56.7)$ \\
\hline No & $55(43.3)$ \\
\hline \multicolumn{2}{|l|}{ Smoker - $n(n \%)$} \\
\hline Yes & $4(3.1)$ \\
\hline No & 123 (96.9) \\
\hline \multicolumn{2}{|l|}{ BMI - $n(n \%)$} \\
\hline Normal & $59(46.5)$ \\
\hline Overweight & $44(34.6)$ \\
\hline Obese & $24(18.9)$ \\
\hline
\end{tabular}

Abbreviation: BMI, body mass index; SD, standard deviation.

Data expressed as mean \pm standard deviation (SD) or absolute and relative frequencies $[\mathrm{n}(\%)]$.

The Portuguese version of the DRSP was applied, and an initial exploration for the discriminant validity of this questionnaire was performed, proving the efficiency of its use for the diagnosis of PMS/PMDD. Confirming the diagnosis of PMS, the - Supplemental Material 3 presents the medians of the DRSP scores for individual questions considering the luteal and follicular phases. The mean follicular phase scores were $\leq 30 \%$ of the luteal phase scores for at least 1 out of 3 different symptoms. Impressively, all of the DRSP items were significantly higher in the luteal phase when compared with the follicular phase, proving the sensitivity of this questionnaire for this purpose. These results support the validation of the DRSP instrument in Portuguese for the Brazilian population.

-Fig. 2 shows that the diagnosis of PMS was higher with the DRSP, and the PMDD diagnosis was higher using the PSST. The percentage of PMS diagnosed by the DRSP was $74.8 \%$, and $41.7 \%$ by the PSST; the percentage of PMDD by the DRSP was $3.9 \%$, and $34.6 \%$ by the PSST. The number of patients that were considered "normal" was similar in both questionnaires.

When we compare the diagnosis in both questionnaires, $70 \%$ of the women considered "normal" by PSST had a PMS diagnosis after the DRSP and 83\% of the women with PMS diagnosis by PSST had the PMS diagnosis confirmed by the DRSP. Otherwise, only $6.8 \%$ of the PMDD diagnosis by the PSST had a 


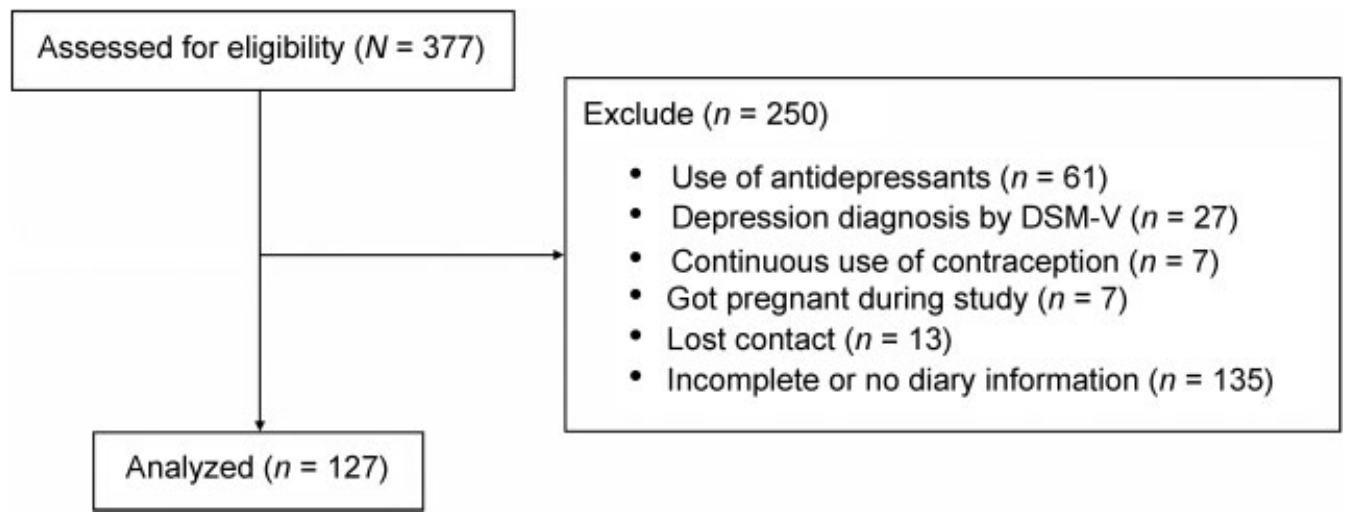

Fig. 1 The flowchart shows the selection process of the participants.

PMDD diagnosis by the DRSP, and 68.2\% of the PMDD diagnosis by the PSST had a PMS diagnosis by the DRSP (- Fig. 3 ).

When considering all the frequencies in the diagnosis categories (Normal, PMS and PMDD) between the DRSP and PSST, an agreement between both instruments could not be observed, as illustrated by the value of the Kappa coefficient $(\mathrm{k}=0.104,95 \% \mathrm{Cl}$ [0.001-0.207], $p=0.039)$. Even when considering the adjusted prevalence through the PABAK coefficient, its value $(0.161,95 \% \mathrm{CI}$ [0.079-0.243] for all diagnosis categories (Normal, PMS and PMDD) is still poorly agreed on between the DRSP and PSST [data not shown]. Additionally, when considering both coefficients comparing the normal and PMS/PMDD categories, the PABAK coefficient value (0.39) showed a moderate consistency between the DRSP and the PSST, although it still fits into a low intensity, according to Altman (1990). ${ }^{19}$ The results of "normal versus PMS/PMDD diagnosis" and "PMS versus PMDD diagnosis" between the PSST and DRSP are displayed in - Table 2.

\section{Discussion}

Experts diverge about the most suitable PMS diagnostic tool. Many group members favored the DRSP; however, more

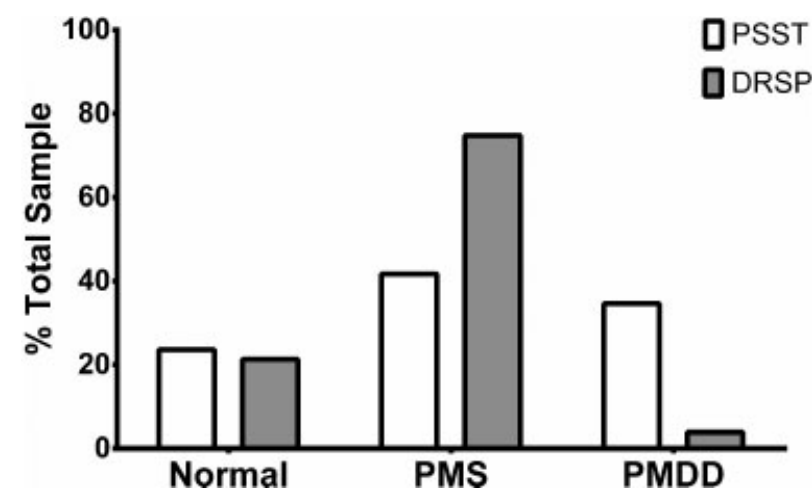

Fig. 2 Comparative prevalence (percentage of total sample) of PMS/ PMDD diagnosis between the PSST and the DRSP. Both instruments presented similar percentages for values falling within normal range. The PMS percentage was 74.8 by DRSP and 41.7 by PSST. The PMDD percentage was 3.9 by DRSP and 34.6 by PSST. Abbreviations: DRSP, daily record of severity problems; PMDD, premenstrual dysphoric disorder; PMS, premenstrual syndrome; PSST, premenstrual symptoms screening tool. simple methods are desirable for clinical use and for screening patients for research studies. ${ }^{11}$

The challenge for the diagnosis and classification of PMS is to distinguish women who need treatment from those without clinical relevance. ${ }^{21}$ The PSST is a fast and effective screening tool and an important starting point for further assessment. $^{14}$

When comparing the data of the PSST with the results of the DRSP, our study shows that the PSST overestimated the diagnosis of PMDD and minimized the diagnosis of PMS. This may be explained by the fact that the PSST data was not collected over time. ${ }^{14}$ However, it is a good screening tool for PMS with a high sensitivity (79\%).

This study points to an important conclusion: we had many losses; 135 women abandoned the recordkeeping, citing the amount of time taken to fulfill the record as a reason for the abandonment. The problem is that filling out the DRSP is a time-consuming process, which is frequently

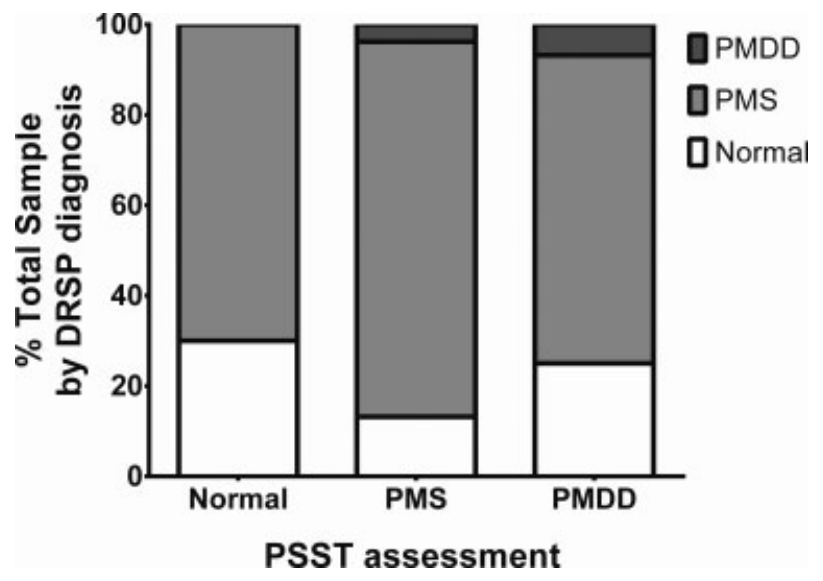

Fig. 3 Assessment of the PSST results according to DRSP diagnosis. Normal percentage by PSST (70\%, light gray column in normal) would be classified as PMS by DRSP diagnosis. Premenstrual syndrome percentage by PSST (83\%, light gray column in PMS) with confirmed PMS diagnosis by DRSP. Premenstrual dysphoric disorder percentage by PSST (6.8\%, darker gray column in PMDD) with confirmed PMDD diagnosis by DRSP. Premenstrual dysphoric disorder percentage by PSST (68.2\%, light gray column in PMDD) would be classified as PMS by DRSP diagnosis. Abbreviations: DRSP, daily record of severity problems; PMDD, premenstrual dysphoric disorder; PMS, premenstrual syndrome; PSST, premenstrual symptoms screening tool. 
Table 2 Evaluation of PMS/PMDD diagnosis using the PSST

\begin{tabular}{|l|l|l|}
\hline Variables & Normal versus PMS/PMDD diagnosis & PMS versus PMDD diagnosis \\
\hline Sensitivity $[95 \% \mathrm{Cl}]$ & $79.00 \%[70.02 \%-85.83 \%]$ & $60.00 \%[23.07 \%-88.24 \%]$ \\
\hline Specificity $[95 \% \mathrm{Cl}]$ & $33.33 \%[18.64 \%-52.18 \%]$ & $59.46 \%[48.08 \%-69.91 \%]$ \\
\hline Positive Predictive value $[95 \% \mathrm{Cl}]$ & $81.40 \%[76.68 \%-85.42 \%]$ & $9.1 \%[4.34 \%-18.06 \%]$ \\
\hline Negative Predictive value $[95 \% \mathrm{Cl}]$ & $30.00 \%[18.32 \%-45.02 \%]$ & $95.7 \%[88.46 \%-98.44 \%]$ \\
\hline Kappa $[95 \% \mathrm{Cl}]$ & $0.119[-0.068-0.305]$ & $0.054[-0.076-0.184]$ \\
\hline$p$ & 0.181 & 0.393 \\
\hline PABAK & 0.39 & 0.19 \\
\hline
\end{tabular}

Abbreviations: $\mathrm{Cl}$, confidence interval; PMDD, premenstrual dysphoric disorder; PMS, premenstrual syndrome.

not followed through. An epidemiological study showed that $30 \%$ of women refused to participate in the study because they did not want to fill out a daily record. The recordkeeping in question may even cause resistance to future treatment offerings. Therefore, it is important to develop economic diagnostic tools for clinical practice. ${ }^{21}$

In a study with 1,477 women, only $56 \%$ completed the DRSP. This study included Brazilian women and showed an elevated incidence of moderate to severe PMS/PMDD: $47.7 \%{ }^{9}$ This demonstrates how difficult it is for women to keep a daily record as part of a research. In the clinical practice, the use of PMS/PMDD diaries is even less frequent.

This study has some limitations. Although 282 women completed the PSST, only 127 women returned with 2 cycles of DRSP filled out. This highlights the difficulty in the application of the DRSP in clinical practice and research, suggesting that the PSST should be used as the initial screening tool.

\section{Conclusion}

Considering that PMS/PMDD have a well-validated diagnostic tool, the DRSP, the PSST should be considered as a screening tool. The PSST underreported the PMS diagnosis and over-estimated the PMDD diagnosis. We recommend that positive cases of PMS/PMDD diagnosed by PSST are further evaluated by using the DRSP.

Contributions

All authors listed above participated in the study to a significant extent. Henz A., Ferreira C. F., Fleck M.P. A. and Wender M.C. O. worked on analysis and interpretation of data, critically reviewed and revised the manuscript. Henz A., Oderich C. L., Gallon C. W., Castro J. R. S., Conzatti M., Fleck M. P. A. and Wender M. C. O. worked on the conception, design and data collection. All authors read and approved the submitted manuscript.

Conflicts to Interest

Authors declare no conflict of interest.

\section{Acknowledgments}

Conselho Nacional de Desenvolvimento Científico e Tecnológico (CNPq, in the Portuguese acronym), Coordenação de Aperfeiçoamento de Pessoal de Nível Superior (CAPES, in the Portuguese acronym) and Fundo de Incentivo à Pesquisa e Eventos/Hospital das Clínicas de Porto Alegre (FIPE/HCPA, in the Portuguese acronym) supported this research. We thank these institutions for their financial support and we would like to express our deepest gratitude to the participants for their time and patience throughout this study.

\section{References}

1 Nillni YI, Rohan KJ, Zvolensky MJ. The role of menstrual cycle phase and anxiety sensitivity in catastrophic misinterpretation of physical symptoms during a $\mathrm{CO}(2)$ challenge. Arch Women Ment Health 2012;15(06):413-422

2 Ryu A, Kim TH. Premenstrual syndrome: A mini review. Maturitas 2015;82(04):436-440

3 Kessel B. Premenstrual syndrome. Advances in diagnosis and treatment. Obstet Gynecol Clin North Am 2000;27(03):625-639

4 Halbreich U, Borenstein J, Pearlstein T, Kahn LS. The prevalence, impairment, impact, and burden of premenstrual dysphoric disorder (PMS/PMDD). Psychoneuroendocrinology 2003;28(Suppl 3):1-23

5 Rodrigues IC, Oliveira E. Prevalência e convivência de mulheres com síndrome pré-menstrual. Arq Ciênc Saúde. 2006;13:146-152

6 Petta CA, Osis MJ, de Pádua KS, Bahamondes L, Makuch MY. Premenstrual syndrome as reported by Brazilian women. Int J Gynaecol Obstet 2010;108(01):40-43

7 Miller FC. Ten goals for the American College of Obstetricians and Gynecologists for the first decade of the next millennium. Obstet Gynecol 2000;95(01):1-5

8 Wittchen HU, Becker E, Lieb R, Krause P. Prevalence, incidence and stability of premenstrual dysphoric disorder in the community. Psychol Med 2002;32(01):119-132

9 Heinemann LA, Minh TD, Filonenko A, Uhl-Hochgräber K. Explorative evaluation of the impact of severe premenstrual disorders on work absenteeism and productivity. Womens Health Issues 2010;20(01):58-65

10 Nevatte T, O'Brien PM, Bäckström T, et al; Consensus Group of the International Society for Premenstrual Disorders. ISPMD consensus on the management of premenstrual disorders. Arch Women Ment Health 2013;16(04):279-291

11 O'Brien PM, Bäckström T, Brown C, et al. Towards a consensus on diagnostic criteria, measurement and trial design of the premenstrual disorders: the ISPMD Montreal consensus. Arch Women Ment Health 2011;14(01):13-21

12 Endicott J, Nee J, Harrison W. Daily Record of Severity of Problems (DRSP): reliability and validity. Arch Women Ment Health 2006;9 (01):41-49

13 Borenstein JE, Dean BB, Yonkers KA, Endicott J. Using the daily record of severity of problems as a screening instrument for premenstrual syndrome. Obstet Gynecol 2007;109(05):1068-1075 
14 Steiner M, Macdougall M, Brown E. The premenstrual symptoms screening tool (PSST) for clinicians. Arch Women Ment Health 2003;6(03):203-209

15 Spitzer RL, Kroenke K, Williams JB. Validation and utility of a selfreport version of PRIME-MD: the PHQ primary care study. Primary Care Evaluation of Mental Disorders. Patient Health Questionnaire. JAMA 1999;282(18):1737-1744

16 Fraguas R Jr, Henriques SG Jr, De Lucia MS, et al. The detection of depression in medical setting: a study with PRIME-MD. J Affect Disord 2006;91(01):11-17

17 American Psychiatric Association. Diagnostic and statistical manual of mental disorders: DSM-5. 5th ed. Washington, DC: American Psychiatric Publishing; 2013
18 Câmara RA, Köhler CA, Frey BN, Hyphantis TN, Carvalho AF. Validation of the Brazilian Portuguese version of the Premenstrual Symptoms Screening Tool (PSST) and association of PSST scores with health-related quality of life. Rev Bras Psiquiatr 2017;39(02):140-146

19 Altman DG. Practical statistics for medical research. London: Chapman \& Hall/CRC; 1990

20 Byrt T, Bishop J, Carlin JB. Bias, prevalence and kappa. J Clin Epidemiol 1993;46(05):423-429

21 Bentz D, Steiner M, Meinlschmidt G. [SIPS-screening instrument for premenstrual symptoms. The German version of Premenstrual Symptoms Screening Tool to assess clinically relevant disturbances]. Nervenarzt 2012;83(01):33-39 